\title{
ACKNOWLEDGEMENTS FROM THE EDITORIAL TEAM
}

We thank the contributors for their participation in this endeavour and for their excellent articles. We are most grateful to the donors for financial support to defray the costs of printing and distribution, without which this Festschrift would not have been possible.

We are especially grateful to the Mauerberger Foundation Fund (MFF) for their generous donation. The MFF requested inclusion of the following comment:

'We are privileged to be associated with such a visionary pioneer, who has made a real difference to so many people'

Other benefactors include:

- The University of Cape Town (UCT), South Africa

- The Faculty of Health Sciences, UCT, South Africa

- The Division of Human Genetics, UCT, South Africa

- Dr and Mrs Michael \& Sandy Hayden, advisers of the Jags Fund, held at the Vancouver Foundation, Canada

- Prof. Ingrid Winship, Melbourne, Australia

- Prof. Maritha Kotze, Stellenbosch University, South Africa 